\title{
Data Mining Autosomal Archaeogenetic Data to Determine Minoan Origins
}

\author{
Peter Z. Revesz \\ University of Nebraska-Lincoln \\ Lincoln, Nebraska, USA \\ revesz@cse.unl.edu
}

\begin{abstract}
This paper presents a method for data mining archaeogenetic autosomal data. The method is applied to the widely debated topic of the origin of the Bronze Age Minoan culture that existed on the island of Crete from 5000 to 3500 years ago. The data is compared with some Neolithic and early Bronze Age samples from the nearby Cycladic islands, mainland Greece and other Neolithic sites. The method shows that a large component of the Minoan autosomal genomes has sources from the Neolithic areas of northern Greece and the rest of the Balkans and a minor component comes directly from Neolithic Anatolia and the Caucasus.
\end{abstract}

\section{CCS CONCEPTS}

- Computing methodologies $\rightarrow$ Machine learning; Machine learning approaches; - Information Systems $\rightarrow$ Data mining; • Applied computing $\rightarrow$ Bioinformatics.

\section{KEYWORDS}

Archaeogenetics, Autosomal, Data Mining, DNA, Minoan

\section{ACM Reference Format:}

Peter Z. Revesz. 2021. Data Mining Autosomal Archaeogenetic Data to Determine Minoan Origins. In 25th International Database Engineering \& Applications Symposium (IDEAS 2021), fuly 14-16, 2021, Montreal, QC, Canada. ACM, New York, NY, USA, 10 pages. https://doi.org/10.1145/3472163.3472178

\section{INTRODUCTION}

The rapid growth of autosomal archaeogenetic data was motivated in recent years by a huge interest in tracking ancient human migrations. Unfortunately, the development of cutting-edge genetic sequencing technologies that have facilitated this rapid growth has not been matched with a proportional development of advanced data mining methods that would bring out the most useful information from the newly available data. The goal of this paper is to introduce a new data mining method that can better answer the deeper questions about human migrations.

In this paper, we show how better data mining of archaeogenetic data can illuminate some widely debated questions about prehistory. In particular, we use the example of the island of Crete. In

Permission to make digital or hard copies of all or part of this work for personal or classroom use is granted without fee provided that copies are not made or distributed for profit or commercial advantage and that copies bear this notice and the full citation on the first page. Copyrights for components of this work owned by others than the author(s) must be honored. Abstracting with credit is permitted. To copy otherwise, or republish, to post on servers or to redistribute to lists, requires prior specific permission and/or a fee. Request permissions from permissions@acm.org.

IDEAS 2021, Fuly 14-16, 2021, Montreal, QC, Canada

(c) 2021 Copyright held by the owner/author(s). Publication rights licensed to ACM. ACM ISBN 978-1-4503-8991-4/21/07 ..\$15.00

https://doi.org/10.1145/3472163.3472178
Crete, there was only a minimal presence of humans during the Paleolithic and the Mesolithic periods, when people lived from fishing and hunting. Agriculture as well as the keeping of sheep, goats, cattle and pigs arrived at Crete from the Near East about 8000 years ago. This is well-documented in archaeology. The Bronze Age started in Crete around 5000 years ago with a civilization that was named the Minoan civilization by Sir Arthur Evans, the famous British archaeologist who discovered the palace of Knossos in central Crete just a few miles south from the modern city of Heraklion, Greece. Even since Arthur Evans' discovery in the early 20th century, people have wondered about where the Minoans came from. Various theories were proposed with no clear answer. Bernal [2] and Evans [10] proposed an Egyptian, Gordon [12] and Marinatos [16] some Near Eastern, Campbell-Dunn [3] Libyan, Haarmann [13] an Old European, and Gimbutas [11] an Anatolian origin of the Minoan civilization. Naturally, Crete's position as an island in the middle of the Mediterranean Sea can lead to many proposals.

One of the motivations of identifying the origins of the Minoan culture is to find the linguistically closest relatives of the Minoans. For example, if they came from Libya, then they may have spoken a Fulani language [3], if they came from the Near East, then they may have spoken a Semitic language such as Phoenician or Ugaritic [12], and if they came from the north, then they may have spoken some Pre-Indo-European language such as Basque, Etruscan or a Finno-Ugric language [21]. The Minoan culture left behind thousands of inscriptions that are considered undeciphered. The identification of related languages can be an important step towards the decipherment of the Minoan scripts.

In this situation, many people hoped that archaeogenetic data will give a definite answer to the question of Minoan origins. However, the archaeogenetic studies were not very conclusive. Moreover, they apparently contradict each other in many details. The earliest Minoan DNA study was published in 2013 by Hughey et al. [14], who examined only mitochondrial DNA (mtDNA). Based only on the mtDNA data, they made the following claim: "Our data are compatible with the hypothesis of an autochthonous development of the Minoan civilization by the descendants of the Neolithic settlers of the island." That means that they thought that the Neolithic settlers of Crete stayed in place and eventually developed their Bronze Age culture. In contrast to Hughey et al. [14], a later mtDNA-based data mining study by Revesz [23] suggested a Danube Basin and Western Black Sea origin of the Minoans.

Lazaridis et al. [15] published the first autosomal, whole-DNA Minoan data in 2017. Lazaridis et al. [15] wrote the following in their conclusion: "Minoans and Mycenaeans were genetically similar, having at least three-quarters of their ancestry from the first Neolithic farmers of Western Anatolia and the Aegean, and most of 
the remainder from ancient populations related to those of the Caucasus and Iran." This again suggested that the Minoan civilization was developed from the local Neolithic settlers. Recently, Clemente et al. [5] succeeded to get more archaeogenetic data from Crete and other islands of the Aegean Sea between Greece and Turkey. Their main conclusion was that the Minoans had over seventy-five percent of ancestry from European Neolithic farmers.

Clearly, the current archaeogenetic results leave a confusing picture. While the genetics researchers have added much valuable data to the genome databases in recent years, their analyses seems confusing and contradictory in some details. This suggests a need for a better data mining of the archaeogenetic data, which we will develop in this paper.

The rest of this paper is organized as follows. Section 2 describes some background to the current study and related previous results. Section 3 describes our data mining method. Section 4 presents some experimental results. Section 5 gives a discussion of the results, including a timeline of the Neolithic and Bronze Age migrations that are implied by our archaeogentic data mining results. Finally, Section 6 gives some conclusions and directions for future work.

\section{BACKGROUND AND PREVIOUS RESULTS}

In this paper, we describe data mining of ancient genomes with a special interest in discovering the origins of two Bronze Age civilizations. The first is the Minoan civilization that existed on the island of Crete, which is shown at the bottom of Fig. 1, and the second is the Cycladic civilization that existed on the other islands above Crete and between present day Greece and Turkey. Currently, the European Nucleotide Archive (ENA) contains two Cycladic and nine Minoan autosomal genomes that were added by Clemente et al. [5] and Lazaridis et al. [15]. The Cycladic civilization is represented by the samples Kou01 and Kou03 from Koufonisia island, while the Minoan civilization is represented by the samples I0070, I0071, I0073, I0074, I9005 from Hagios Charalambos Cave, Crete, samples I9129, I9130, I9131 from Moni Odigitria, Crete, and Pta08 from Petras, Crete. These autosomal genomes will be compared with autosomal genomes from other Neolithic samples. Fig. 1 shows the location of some of the Aegean samples.

Admixture analysis is an important method in genetic testing. The basic goal of admixture analysis is to find the possible sources of a test sample Test. In an admixture analysis, some possible options Ref1, Ref2, .., Refn are given. Essentially, an admixture analysis compares the genes of the Test and the corresponding genes of the possible sources. The admixture analysis tallies how many times each possible source had a corresponding gene that was closest to the gene of Test among all of the sources. For example, the result of an admixture analysis may be that the Test is composed of 50 percent of Ref1, 30 percent of Ref2, and 20 percent of Ref3. Sometimes, the possible source population is not just one genome sample but a small set of related samples, for example, all the samples from the Minoan site of Moni Odigitria. In this case, several corresponding genes can be considered from this group with always the best out of those being chosen. In practice, the number of possible source populations is limited to a small number, because a full admixture analysis is a computationally complex task.
Clemente et al. [5] did an admixture analysis of some Bronze Age Aegean samples from the Cycladic, Minoan and Mycenaean cultures as shown in Fig. 2. They grouped these samples according to the following time periods: Early Bronze Age (EBA), Middle Bronze Age (MBA) and the Late Bronze Age (LBA). Fig. 2 shows their main results about how their Aegean samples (Test column) can be explained by two hypothetical source populations (Ref1 and Ref2 columns). As can be seen from Fig. 2, their source populations were the Aegean samples listed as Kou01, Kou03, Mik15, Log02, Log04, Mik15, Minoan_Lasithi, Minoan_Odigitria, and Mycenaean. In addition, they considered the following source populations: some of the Aegean samples themselves, Anatolian Neolithic (Anatolia_N), Balkans Late Bronze Age (Balkans_LBA), Caucasian Hunter-Gatherer (CHG), Europe Late Neolithic and Bronze Age (Europe_LNBA), Eastern European Hunter-Gatherer (EHG), Iranian Neolithic (Iran_N), Pontic Steppe Early and Middle Bronze Age (Steppe_EMBA), Pontic Steppe Middle and Late Bronze Age (Steppe_MLBA), and Western European Hunter-Gatherer (WHG).

Clemente et al. [5] apparently did not consider the European Early Neolithic and European Middle Neolithic cultures as possible sources for the Aegean samples. Lazaridis et al. [15] also did not consider those types of samples. Revesz [23] considered European Neolithic mitochondrial DNA samples from the Danube Basin and suggested that some migration took place from the Danube Basin to Crete during the Bronze Age. Our study extends the earlier works by considering autosomal, whole DNA data and include European Early and Middle Neolithic samples too.

\section{DATA MINING METHOD}

We have used the G25 admixture analysis package [25]. The G25 admixture analysis package already represents over a thousand archaeogenetic samples or small sets of samples as possible options to select for sources. While the previous studies limited their possible sources to a few selected ones, we did not preselect any particular source and instead considered all available Neolithic autosomal data as potential sources. This approach can avoid the different conclusions of the previous studies that were due to preselecting a very limited number of sources for consideration, while excluding hundreds of other possible sources from consideration.

Our data mining analysis started with the following open-ended question: Where did the Neolithic ancestors of the Minoans live? This question was completely open-ended, because we did not restrict the set of possible sources that the G25 package could choose from. Our approach was to look as widely as possible for potential sources among all Old World Neolithic, Mesolithic and Paleolithic samples from the G25 database, which was a total of 271 potential sources. Then we concurrently tested all of them as potential sources for each of the eleven Aegean samples. For each test sample, the G25 admixture analysis system listed all the hypothetical sources with a decreasing percentage order. Two examples of the G25 output results are shown in Fig 3. On the top we see the results for the Minoan sample I0070, whose origins are 51.8 percent Greek Peloponnese Neolithic, 29.6 percent other Greek Neolithic, 11.8 percent Caucasus Lowland from Azerbaijan, 6.6 percent Caucasian Hunter-Gatherer from Georgia, and 0.2 percent Pre-Pottery 


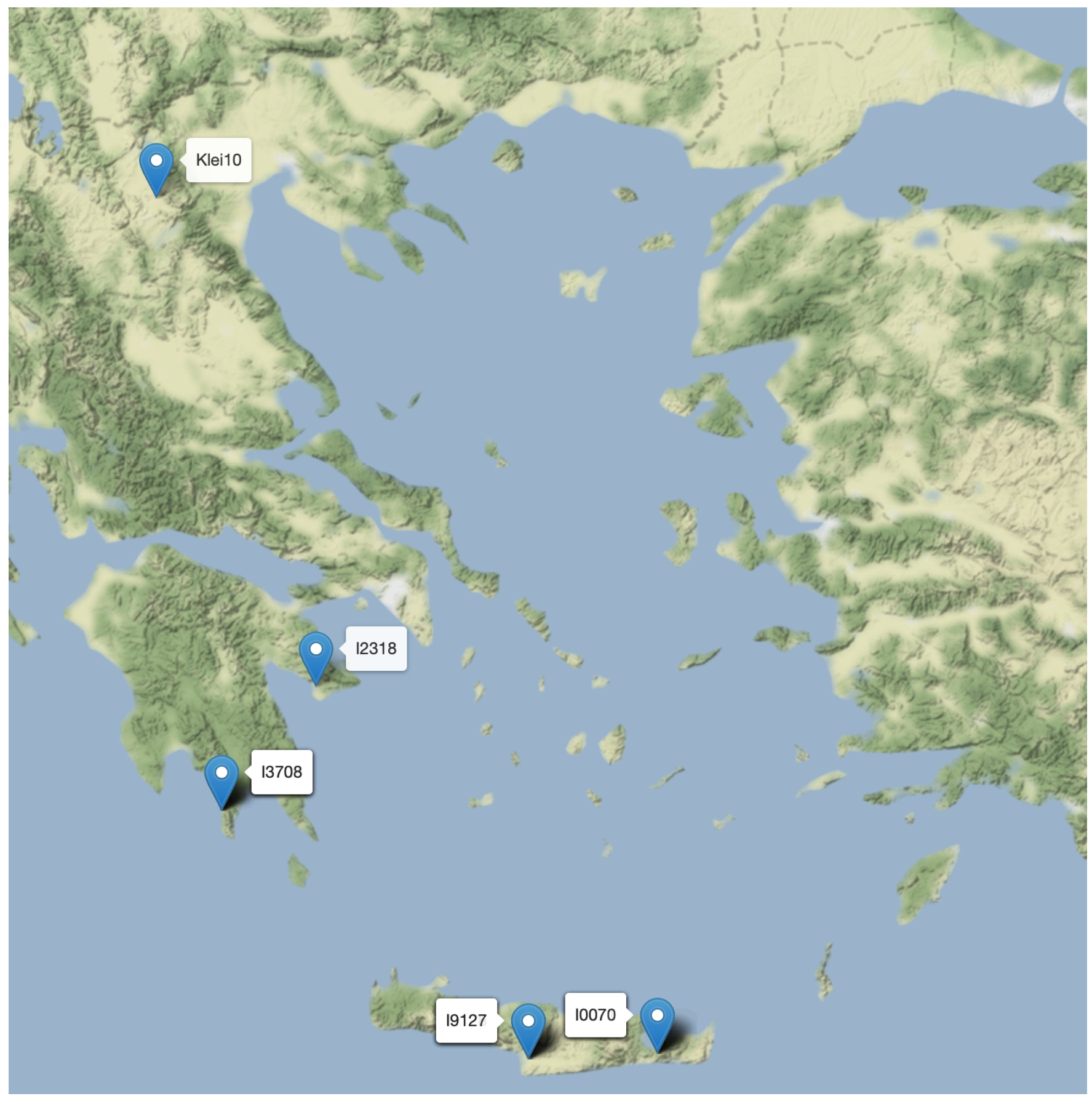

Figure 1: The location of some of the Minoan samples. On the island of Crete, shown on the bottom of the map, the sample I9127 belongs to Moni Odigitria, and the sample I0070 belongs to the Charalambos Cave. This map was generated based on the amtDB database [9]

Neolithic Culture B (PPNB) from the Levant. Below this there is another example regarding the Minoan sample from Petras identified by Pta08. Clearly, this has a very different origin. In fact, its hypothetical sources are 49.4 percent the Neolithic Starcevo Culture from Hungary, 33.6 percent Caucasus Lowland from Azerbaijan, 7.6 percent Linear Pottery Culture (LBK) from Germany, 5.2 percent Middle Neolithic Alföld Culture from Hungary, 2.6 Neolithic 


\begin{tabular}{|c|c|c|c|c|c|c|c|c|}
\hline Period & Test & Ref1 & Ref2 & Ref3 & $\begin{array}{l}\text { Mixture Prop. } \\
\text { Ref1 } \pm \text { SE }\end{array}$ & $\begin{array}{l}\text { Mixture Prop. } \\
\text { Ref2 } \pm \text { SE }\end{array}$ & $\begin{array}{l}\text { Mixture Prop. } \\
\text { Ref3 } \pm \text { SE }\end{array}$ & $p$ value \\
\hline \multirow[t]{10}{*}{ EBA } & Kou01 & Anatolia_N & $C H G$ & & $0.75 \pm 0.03$ & $0.25 \pm 0.03$ & & 0.67 \\
\hline & Kou01 & Anatolia_N & Iran_N & & $0.75 \pm 0.03$ & $0.25 \pm 0.03$ & & 0.90 \\
\hline & Коu03 & Anatolia_N & $\mathrm{CHG}$ & & $0.69 \pm 0.03$ & $0.31 \pm 0.03$ & & 0.10 \\
\hline & Mik15 & Anatolia_N & $\mathrm{CHG}$ & & $0.84 \pm 0.03$ & $0.16 \pm 0.03$ & & 0.08 \\
\hline & Mik15 & Anatolia_N & Iran_N & & $0.84 \pm 0.03$ & $0.16 \pm 0.03$ & & 0.07 \\
\hline & Pta08 & Mik15 & Iran_N & & $0.98 \pm 0.03$ & $0.02 \pm 0.03$ & & 0.09 \\
\hline & Pta08 & Mik15 & $C H G$ & & $0.99 \pm 0.03$ & $0.01 \pm 0.01$ & & 0.07 \\
\hline & Kou01 & Anatolia_N & $C H G$ & $E H G$ & $0.74 \pm 0.04$ & $0.25 \pm 0.03$ & $0.01 \pm 0.02$ & 0.67 \\
\hline & Kou01 & Anatolia_N & Iran_N & $E H G$ & $0.74 \pm 0.03$ & $0.24 \pm 0.03$ & $0.02 \pm 0.02$ & 0.88 \\
\hline & Kou03 & Anatolia_N & Iran_N & $E H G$ & $0.67 \pm 0.03$ & $0.25 \pm 0.03$ & $0.08 \pm 0.02$ & 0.82 \\
\hline \multirow[t]{13}{*}{ MBA } & $\log 02$ & Kou01 & $E H G$ & & $0.81 \pm 0.02$ & $0.19 \pm 0.02$ & & 0.07 \\
\hline & $\log 02$ & Kou03 & $W H G$ & & $0.91 \pm 0.02$ & $0.09 \pm 0.02$ & & 0.06 \\
\hline & $\log 02$ & Anatolia_N & Balkans_LBA & $\mathrm{CHG}$ & $0.22 \pm 0.05$ & $0.65 \pm 0.06$ & $0.12 \pm 0.04$ & 0.08 \\
\hline & $\log 02^{*}$ & Kou01 & Steppe_MLBA & & $0.61 \pm 0.03$ & $0.39 \pm 0.03$ & & 0.20 \\
\hline & $\log 02^{*}$ & Kou01 & Europe_LNBA & & $0.56 \pm 0.04$ & $0.44 \pm 0.04$ & & 0.05 \\
\hline & $\log 04$ & Kou01 & Balkans_LBA & & $0.21 \pm 0.06$ & $0.79 \pm 0.06$ & & 0.08 \\
\hline & $\log 04$ & Kou03 & Balkans_LBA & & $0.26 \pm 0.07$ & $0.74 \pm 0.07$ & & 0.07 \\
\hline & $\log 04$ & Mik15 & Balkans_LBA & & $0.21 \pm 0.06$ & $0.79 \pm 0.06$ & & 0.06 \\
\hline & $\log 04$ & Anatolia_N & $C H G$ & $E H G$ & $0.58 \pm 0.03$ & $0.16 \pm 0.03$ & $0.27 \pm 0.02$ & 0.12 \\
\hline & $\log 04^{*}$ & Anatolia_N & Steppe_EMBA & & $0.53 \pm 0.03$ & $0.47 \pm 0.03$ & & 0.35 \\
\hline & $\log 04^{*}$ & Anatolia_N & Steppe_MLBA & & $0.38 \pm 0.03$ & $0.62 \pm 0.03$ & & 0.13 \\
\hline & $\log 04^{*}$ & Pta08 & Balkans_LBA & & $0.15 \pm 0.04$ & $0.85 \pm 0.04$ & & 0.06 \\
\hline & $\log 04^{*}$ & Pta08 & Steppe_MLBA & & $0.44 \pm 0.03$ & $0.56 \pm 0.03$ & & 0.36 \\
\hline \multirow[t]{3}{*}{ LBA } & Mycenaean & $\log 04$ & Minoan_Lasithi & & $0.36 \pm 0.04$ & $0.64 \pm 0.04$ & & 0.35 \\
\hline & Mycenaean & $\log 04$ & Minoan_Odigitria & & $0.21 \pm 0.04$ & $0.79 \pm 0.04$ & & 0.45 \\
\hline & Mycenaean & Anatolia_N & Kou03 & & $0.37 \pm 0.09$ & $0.63 \pm 0.09$ & & 0.40 \\
\hline
\end{tabular}

Figure 2: The admixture analysis results of Clemente et al. [5] about how their Aegean samples' (Test column) can be explained by two hypothetical source populations (Ref1 and Ref2 columns).

Tepecik-Ciftlik Culture from Turkey, 1.4 percent Pre-Pottery Neolithic Culture B (PPNB) from the Levant, and 0.2 percent from Late Neolithic Malaysia.

\section{EXPERIMENTAL RESULTS}

From all the G25 admixture analysis system outputs, we created a table as shown in Fig. 4, where each row represents a culture that was a source of one of the eleven Cycladic or Minoan samples. We only list those rows that had some non-zero value for at least one of the eleven Cycladic and Minoan test samples. In each column, the percentages add up to 100 percent, meaning that the hypothetical sources are fully accounted.

In Fig. 4 we present the data by grouping the sources together according to regions, using a separate color for each region. African sources are shown in yellow, Greek and Macedonian sources are shown in dark blue, other European sources, which are almost all from the Danube Basin, are shown in light blue, Caucasian, Ukrainian, and Russian Siberian sources are shown in orange, while Fertile Crescent and Iranian sources are shown in green.

\subsection{Detection of African Origin}

The African DNA sample is from a hunter-gatherer from the Shum Laka rock shelter in Cameroon about 8000 years ago. Although the connection is only 0.6 percent for the sample 19129, it suggests that as the Sahara dried out, some people moved north into Europe, and apparently reached the island of Crete, while another group moved south to Sub-Saharan Africa. This explains some of the linguistic connections that were found between African and European mountain names [21]. This is the first time an African genetic connection was detected to the Minoans in any study.

\subsection{Minoan groups at Charalambos Cave and Moni Odigitria are Distinct}

Fig. 5 shows the clusters that we obtain after finding the averages for each location and then separating the low values between 0 and 34 (sky blue) and high values between 42 and 73 (red). It is now apparent that the Cycladic Koufonisi and the Minoan Charalambos Cave samples cluster together, while the Minoan Moni Odigitria and 


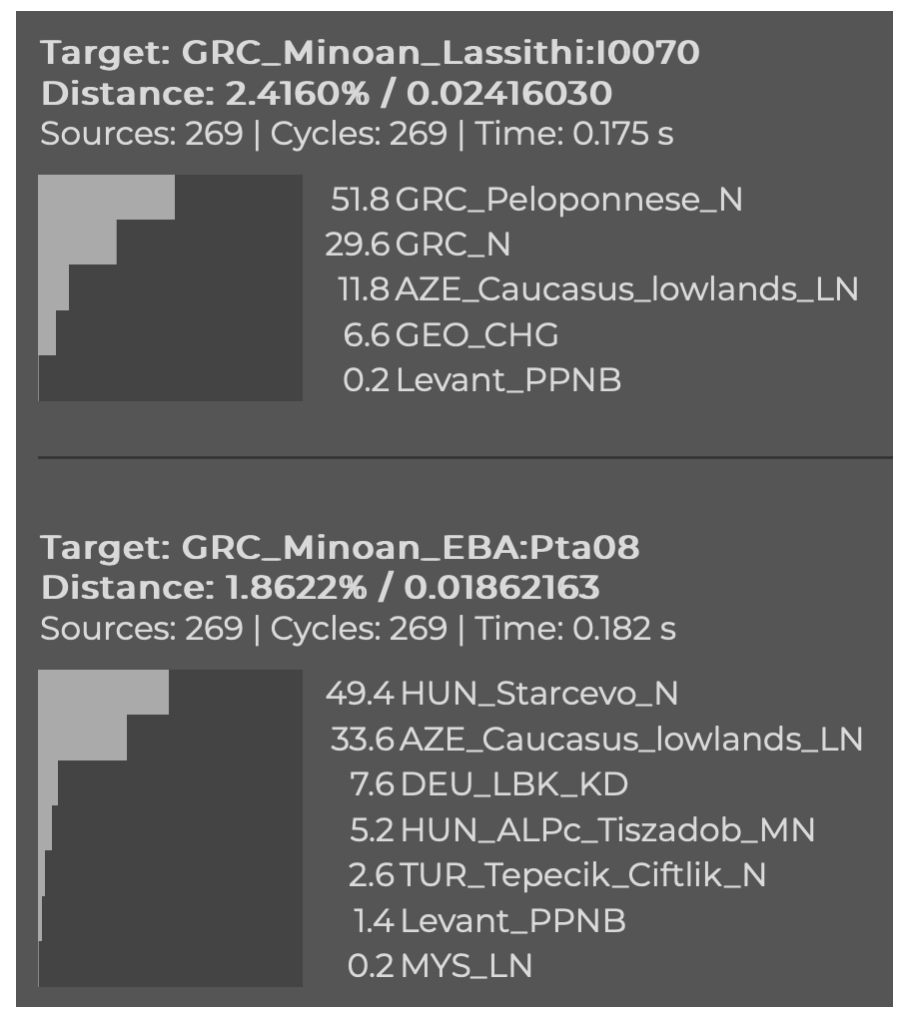

Figure 3: Example data output of the G25 admixture analysis system.

Petras samples cluster together. Clemente et al. [5] and Lazaridis et al. [15] did not note any differences between the Charalambos Cave and the Moni Odigitria groups.

\subsection{Principal Component Analysis}

Fig. 6 shows a Principal Component Analysis (PCA) of various Neolithic, Chalcolithic and Bronze Age samples from Anatolia and Southeastern Europe that are also used in Fig. 4 with the addition of a few Mycenaean samples that we added as extra for comparison.

The PCA components were automatically generated by a free PCA software tool developed for the G25 admixture analysis system and available on its github page. The first and the second principal components are mapped to the $x$ and the $y$ axes of Fig. 6. Clearly, the African, Caucasian, and Fertile Crescent samples are all either greater than -0.1 on the $x$-axis or less than -0.05 on the $y$-axis except some Turkish Neolithic samples, while the Danube Basin and Greek samples are the opposite, i.e., less than -0.1 on the $x$-axis or greater than -0.05 on the $y$-axis except the Corded Ware samples. Hence, the Corded Ware samples appear to have a mixed Caucasus and Danube Basin ancestry.

Fig 7 shows a detail of Fig. 6. The detail shows that the (mostly northern) Greek Neolithic samples are closest to the Hungarian Körös early Neolithic samples except the separate group of Greek Peloponnese Neolithic samples. The Charalambos Cave (marked as GRC_Lassithi_Plateau), the two Cycladic (GRC_Cycladic_EBA) and the Petras (GRC_Minoan_EBA) samples are increasingly below and to the right of the Greek Neolithic samples. This suggests a migration from the Danube Basin to Greece with the Danube Basin signature diminishing with increasingly heavy local admixture in the Peloponnese peninsula, the Cyclades and Crete. Some of the local population may have come from Anatolia as indicated by the locations of the Anatolian Neolithic samples from Kumtepe and Tepecik_Ciftlik.

The five Charalambos Cave samples and the three Moni Odigitria samples form two different clusters without any overlap. The Moni Odigitria samples are all above the Greek Peloponnese Neolithic samples and much above the Charalambos Cave, Cycladic and Petras samples. The Moni Odigitria samples are close to several Danube Basin Middle Neolithic samples. This suggests another migration from the Danube Basin to Crete.

Finally, the Mycenaean samples are considerably to the right of the Minoan samples, suggesting that they are a mixture of Minoan and Caucasian origin.

\section{DISCUSSION OF THE RESULTS}

Based on radiocarbon dating the estimated age of the Moni Odigitria samples ranges from 2210 to $1600 \mathrm{BC}$, while the estimated age of the Charalambos Cave samples ranges from 2000 to 1700 BC [15]. Therefore, the Moni Odigitria samples seem older. The Petras sample is even older with an estimated date rage from 2849 to $2621 \mathrm{BC}$ [5]. Therefore, it is logical that the Moni Odigitria and 


\begin{tabular}{|c|c|c|c|c|c|c|c|c|c|c|c|}
\hline & Kou01 & Kou03 & 10070 & 10071 & 10073 & 10074 & 19005 & 19129 & 19130 & 19131 & Pta08 \\
\hline CMR_Shum_Laka_8000BP & & & & & & & & 0.6 & & & \\
\hline GRC_N & & 13.4 & 29.6 & 18 & 13 & & 13 & & & & \\
\hline GRC_Peloponnese_N & 21.4 & 49.2 & 51.8 & 49.6 & 28.8 & 35.4 & 40.8 & & 19.6 & 9 & \\
\hline MKD_N & & & & & & & 31.2 & & & & \\
\hline total Greece & 21.4 & 62.6 & 81.4 & 67.6 & 41.8 & 35.4 & 85 & 0 & 19.6 & 9 & 0 \\
\hline BGR_Krepost_N & & & & 18.2 & & 7.6 & & & & 27.4 & \\
\hline Corded_Ware_DEU & 0.6 & & & & & & & & & & \\
\hline Corded_Ware_POL_early & & & & & & & & & & 1.6 & \\
\hline DEU_LBK_KD & 1 & & & 3.6 & & 3.2 & & & 33.4 & 6 & 7.6 \\
\hline DEU_LBK_SCH & & & & & & & & 2.8 & & & \\
\hline DEU_LBK_UW & & 4.6 & & & & & & & & & \\
\hline FRA_Grand_Est_EN & & & & & & & & 4.2 & & & \\
\hline HUN_ALPc_I_MN & & & & & & & & 10.6 & & & \\
\hline HUN_ALPc_Tiszadob_MN & & & & & & & & & 13.8 & & 5.2 \\
\hline HUN_Koros_N & & & & & & & & & & 45.6 & \\
\hline HUN_LBK_MN & & & & & 32.4 & & & & & & \\
\hline HUN_Sopot_LN & & & & & & & & & 13.8 & & \\
\hline HUN_Starcevo_N & 13.4 & & & & & 32.2 & & & & & 49.4 \\
\hline ROU_N & & 10.4 & & & & & & 47.4 & & & \\
\hline SRB_N & 3.4 & & & & & & & 2.4 & & & \\
\hline SRB_Starcevo_N & & & & & & & & 7.2 & & & \\
\hline total Danube Basin & 18.4 & 15 & 0 & 21.8 & 32.4 & 43 & 0 & 74.6 & 61 & 80.6 & 62.2 \\
\hline AZE_Caucasian_lowlands_LN & 24.2 & & 11.8 & 2.8 & 6.6 & 20.4 & 6.4 & & & & 33.6 \\
\hline GEO_CHG & & 8.6 & 6.6 & 7.8 & 3 & & 8.6 & & 2.6 & 6.6 & \\
\hline RUS_AfantovaGora3 & & 2 & & & & & & & & & \\
\hline RUS_Yakutia_N & & & & & 0.2 & 0.8 & & & & & \\
\hline RUS_Yakutia_Ymyiakhatkh_LN & & & & & & 0.4 & & & & & \\
\hline UKR_N & 14 & & & & & & & & & & \\
\hline total Caucasus & 38.2 & 10.6 & 18.4 & 10.6 & 9.8 & 21.6 & 15 & 0 & 2.6 & 6.6 & 33.6 \\
\hline IRN_Seh_Gabi_LN & & 11.8 & & & & & & & 10 & & \\
\hline IRN_Wezmeh_N & & & & & 3.8 & & & 10.2 & & & \\
\hline Levant_PPNB & & & 0.2 & & & & & & & & 1.4 \\
\hline Levant_PPNC & & & & & & & & & & 3.8 & \\
\hline MYS_LN & & & & & & & & & & & 0.2 \\
\hline TUR_Tepecik_Ciftlik_N & 0.8 & & & & & & & & 6.8 & & 2.6 \\
\hline TUR_Kumtepe_N & 21.2 & & & & 12.2 & & & 14.6 & & & \\
\hline total Fertile Crescent & 22 & 11.8 & 0.2 & 0 & 16 & 0 & 0 & 24.8 & 16.8 & 3.8 & 4.2 \\
\hline
\end{tabular}

Figure 4: The Neolithic sources for various Cycladic and Minoan autosomal DNAs according to the G25 admixture analysis system.

the Petras samples cluster together in Fig. 5. This clustering is partially supported by Fig. 7 where the Moni Odigitria and the Petras samples have the same $x$-axis. However, they have a significantly different Caucasus admixture. The Caucasus admixture of the Petras sample is based on AZE_Caucasian_lowlands_LN, which is located almost directly below the Petras sample. Hence it is likely that the Petras sample is lower than the Moni Odigitria samples due to the higher AZE_Caucasian_lowlands_LN admixture.
Based on our data mining, we can reconstruct the following sequence of events and illustrate them in Fig. 8.

(1) The Neolithic agricultural revolution started in the Fertile Crescent and spread from there via three routes that are relevant to our study. The first and the second routes went slowly through Anatolia, where the spread of agriculture took two different turns. One route continued along the eastern Black Sea until the Danube Delta and then followed the Danube 


\begin{tabular}{|l|c|c|c|c|}
\hline & Koufonisi & Charalambos Cave & Moni Odigitria & Petras \\
\hline Greece + Macedonia & 42 & 62.24 & 9.53 & 0 \\
\hline Danube Basin & 16.7 & 19.44 & 72.07 & 61.8 \\
\hline Caucasus & 24.4 & 15.08 & 3.07 & 33.4 \\
\hline Fertile Crescent & 16.9 & 3.24 & 15.13 & 4.6 \\
\hline
\end{tabular}

Legend: \begin{tabular}{|l|l|l|}
$0-20$ & $24-34$ & $42-100$ \\
\hline
\end{tabular}

Figure 5: The cluster analysis of the four different Aegean locations.

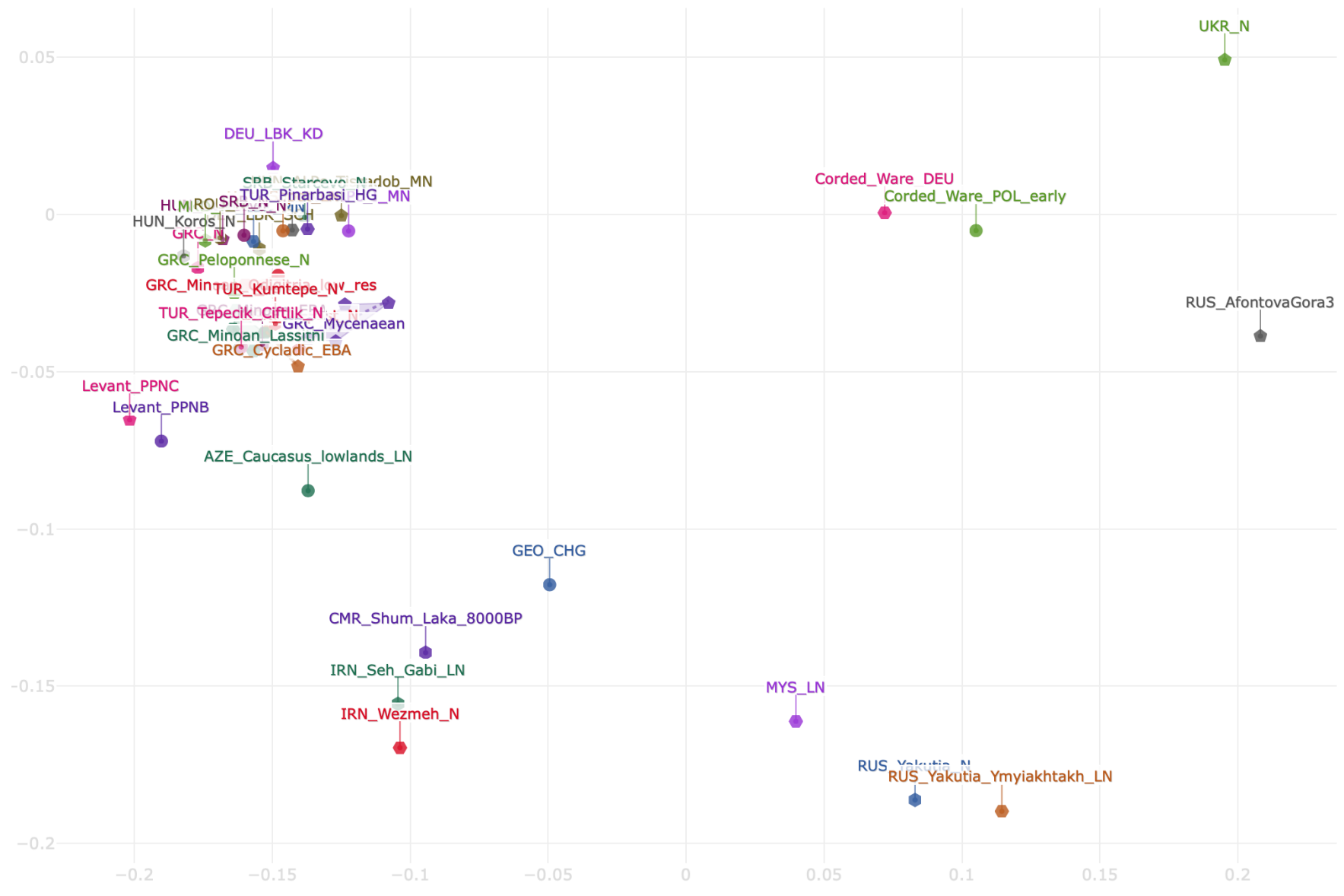

Figure 6: A PCA analysis of the archaeogenetic samples in Figure 4.

as the gateway into Europe. The early European Farmers who followed this route established the Old European civilization [11]. This culture is divided into various groups such as the Vinča culture, the Körös culture, etc. The second route went along the cost of Southern Europe, reaching from Greece to the Iberian peninsula. The farmers on this second route area are known for their Cardium pottery culture [11] A third route of agricultural expansion expanded toward the
Caucasus. Initially, these three groups kept separate from each other, but later there was considerable interaction and apparent convergence of material culture between these areas. Childe[4] describes archaeological similarities between the Old European civilization in the Danube Basin and the Neolithic Dimini culture in Greece. Revesz [22] traces the spread of art motifs that accompanied the early Neolithic and the Bronze Age human migrations. Revesz [22] reports 


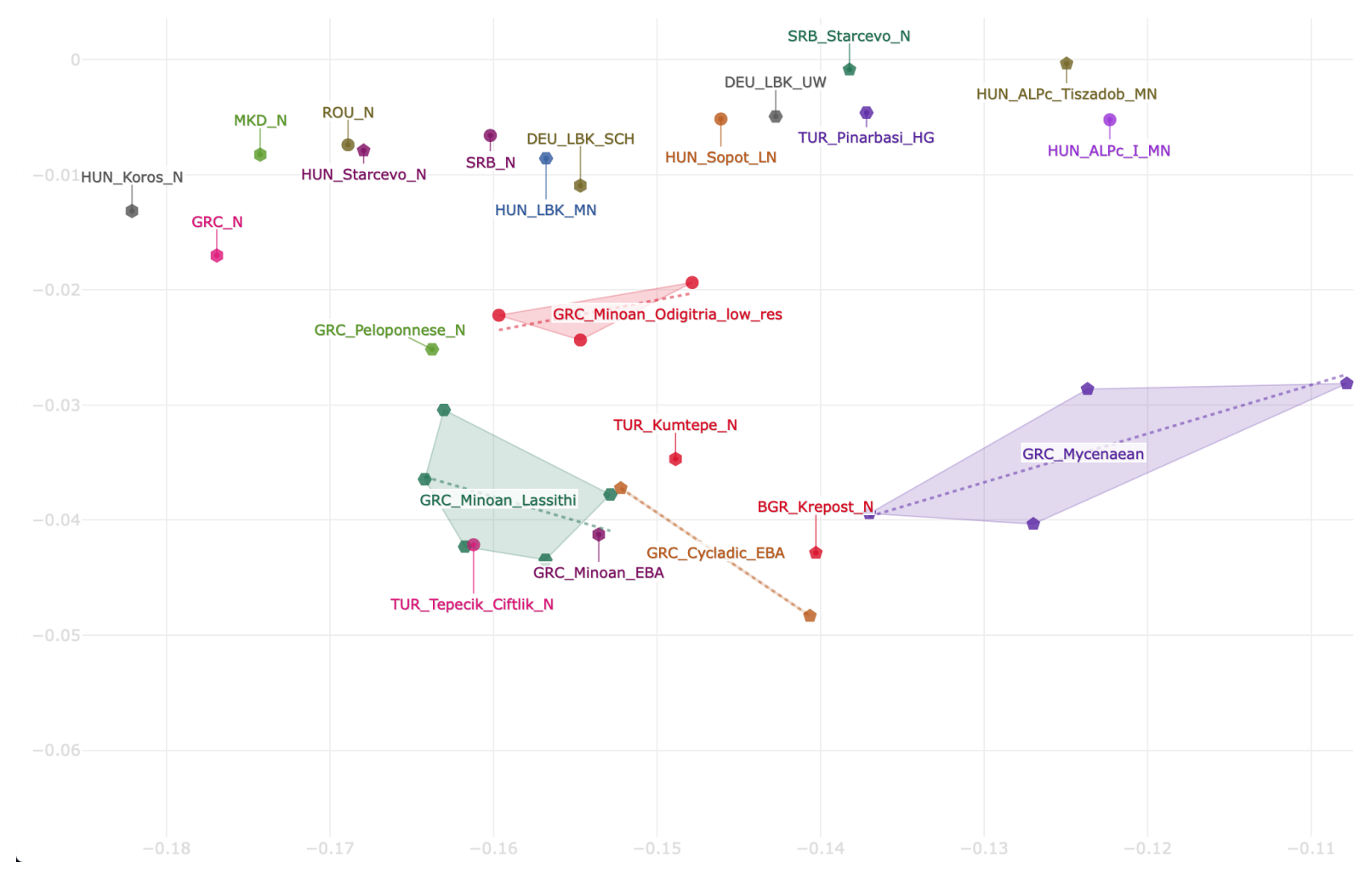

Figure 7: PCA detail with the Minoan Charalambos Cave samples, Moni Odigitria samples, and the Greek Peloponnese Neolithic samples. The polygons indicate the clusters of all Minoan Charalambos, all Minoan Moni Odigitria and one group of Greek Mycenaean samples.

a particularly strong connection between the late Neolithic and early Bronze Age Danube Basin cultures and the Minoan culture.

There was also some early population movement from the Caucasus, which has effected the eastern part of Crete the most, as evidenced by the high Caucasus lowland ancestry of the Petras sample as seen in Fig. 4.

(2) At the beginning of the Early Bronze Age, about 5000 years ago, the Minoan culture was established by people who moved from mainland Greece and Macedonia and to a lesser extent from the Caucasus lowland area to the Cyclades and to Crete as shown in Fig. 8. The EBA migration seems to have affected the Cyclades, including the island of Koufonisi, and the northern and central part of Crete, including the Charalambos Cave on the Lassithi Plateau, according to the cluster analysis in Section 4.2. The PCA analysis suggests that the Charalambos Cave samples genetically originated from the Greek mainland, especially the Peloponnese peninsula, but they mixed with people who came from the Caucasus. Concurrently, some EBA migration could have occurred to eastern Crete from the Danube Basin area, which was part of the Old European civilization [11]. This may explain the high concentration of Danube Basin ancestry in the Petras sample.
The migration to Petras could have been easily done by ship starting from the Danube Delta area and sailing through the Bosporus Strait and the Dardanelles Strait to the Aegean Sea and then following the western cost line of Anatolia as shown in Fig. 8.

Possible Cause: According to Kurgan Hypothesis [11], the first groups of Indo-Europeans started to move from the Pontic Steppe to Central and Southeastern Europe around 5000 years ago. Hence, it seems that the Indo-European migration, and in particular the migration of Mycenaeans to the Peloponnese area caused some of the populations to move south to the Cyclades and Crete.

(3) At the beginning of the Middle Bronze Age, about 4200 years ago, the Middle Minoan culture was created by another movement of people to Crete from the Danube Basin area. This wave of migration also followed the shipping route shown in Fig. 8 but apparently after reaching the eastern end of Crete, people sailed along the southern cost of Crete in an east-to-west direction before reaching Hagia Triada, a natural harbor near Moni Odigitria. This hypothesis is supported by the remarkably high Danube Basin admixture and no Caucasus lowland admixture in the Moni Odigitria samples 


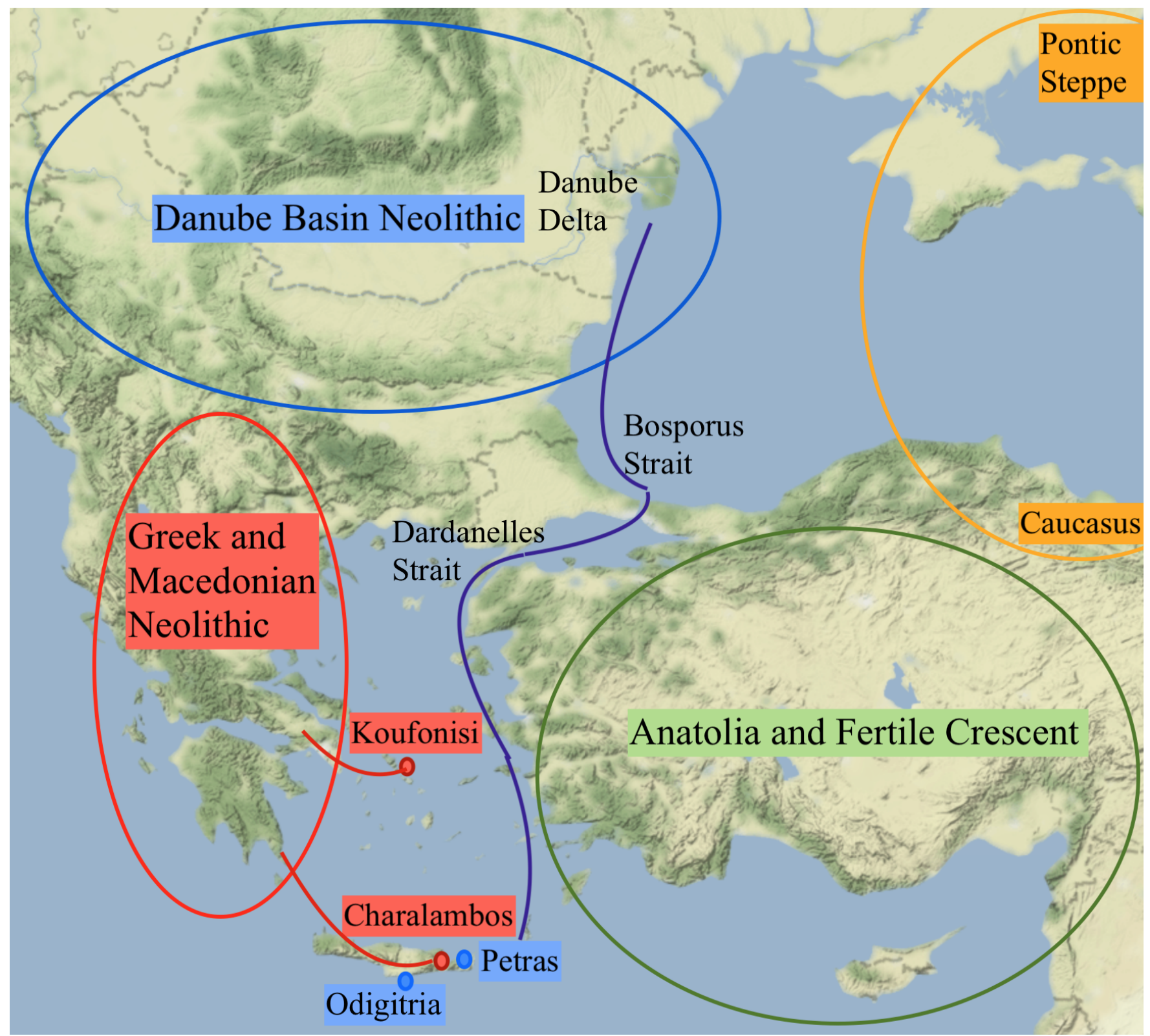

Figure 8: Some of the Aegean migration routes implied by the archaeological data mining.

as shown by both the cluster analysis in Section 4.2 and the PCA analysis in Section 4.3.

In addition, Haiga Triada is the largest source of Minoan Linear A documents. According to Revesz [20], the underlying language of Linear A belongs to the Finno-Ugric language family. Ancient topological names suggest that some people in the Black Sea area spoke Finno-Ugric languages before the arrival of Indo-Europeans [21]. At the Phaistos palace, which is also near Moni Odigitria, the Phaistos Disk was found, which shows another form of Minoan writing that is related to Cretan Hieroglyphs. These Minoan scripts share the same underlying language with Linear A $[17,18]$. The AIDA system provides an online, searchable library of Minoan inscriptions with their translations [24]. Cretan Hieroglyphs, Linear A and the Phaistos Disk script are members of the Cretan Script Family, which also includes the Linear B script that was used by the Mycenaeans [19]. The adoption of Linear A to Linear B was accompanied by a language change, where the signs were reinterpreted in the Mycenaean Greek language, which resulted in a change of the phonetic values of many of the signs. Daggumati and Revesz [6] use convolutional neural networks to extend the script comparison 
to other ancient scripts, including the Indus Valley Script, which also has boustrophedon writing and a large number of allographs [7].

Possible Cause: This migration may have been prompted by a major climate change event, which is called the 4.2 kiloyear BP aridification event [8], when many areas of the world, including the Danube Basin, became dryer, making those areas infeasible for agriculture. Hence, farmers likely moved from those agricultural areas to the Aegean islands, which provided good fishing opportunities.

(4) In the Late Bronze Age, around 1450 BC, the Mycenaeans conquered Crete. They established Knossos as the main center on Crete and modified the Minoan Linear A writing into Linear B, which records the earliest form of Greek language.

Possible Cause: The Santorini volcanic eruption c. 1600 $\mathrm{BC}$ resulted in a large tsunami that may have destroyed many of the Minoan coastal towns and the shipping fleet [1] The volcanic eruption likely did not affect the Mycenaeans as negatively as the Minoans because while the tsunami hit northern Crete, it avoided the Argolis area, where the Mycenaeans lived. Hence the Mycenaean civilization could recover faster than the Minoan civilization after this catastrophe. As a result, the Mycenaeans became relatively stronger. Their surviving ships may have taken over some of the commercial activities of the Minoans when the latter's fleet was destroyed.

\section{CONCLUSION AND FUTURE WORK}

Most of the farmers in the Danube Basin had ancestry from $\mathrm{Ne}$ olithic Anatolia. We are the first to test autosomal DNA for source ancestry from both populations simultaneously. The finding that the Neolithic Danube Basin is closer to the Moni Odigitria and Petras samples than to Neolithic Anatolian samples is surprising and contradicts the earlier hypothesis of Lazaridis et al. [15], which we quoted in the introduction. It also clarifies the confusion that Clemente et al. [5] introduced by grouping these two groups together into a "Neolithic European" category.

Archaeogenetic data mining cannot give a full answer to the question of what language was spoken by various groups in Southeastern Europe. Our archaeogenetic study suggests that the Early Minoan language may be related to some language spoken in the Greek Peloponnese peninsula around 5000 years ago, and the Middle Minoan language may be related to some language spoken in the Danube Basin area about 4200 years ago. The linguistic identification of the underlying language of Minoan Linear A as a FinnoUgric language [20] tends to support our autosomal data mining results because part of the Danube Basin and the western Black Sea areas likely were Finno-Ugric language areas before the arrival of the Indo-Europeans. Some Neolithic Danube Basin archaeological sites contain undeciphered inscriptions in a script that resembles the Linear A script. That raises the possibility that the Linear A script was brought to Crete from the Danube Basin. However, more research is needed regarding the relationship between the Danube Basin script and the Minoan scripts.

\section{REFERENCES}

[1] J. Antonopoulos. 1992. The great Minoan eruption of Thera volcano and the ensuing tsunami in the Greek Archipelago. Natural Hazards, 5, 153?168.

[2] M. Bernal. 2006. Black Athena: The Afroasiatic Roots of Classical Civilization: The Linguistic Evidence, vol. III, Rutgers University Press, New Brunswick, NJ, USA.

[3] G. Campbell-Dunn. 2014. Who were the Minoans?: An African Answer. BookWhirl Publishing: Green Bay, WI, USA.

[4] V. C. Childe. 1922. The East-European relations of the Dimini Culture, The fournal of Hellenic Studies, vol. 42, no. 2, 254-275.

[5] F. Clemente, M. Unterlánder, O. Dolgova, C. Eduardo, C., G. Amorim, F. CoroadoSantos, S. Neuenschwander, E. Ganiatsou, M. I. Cruz Dávalos, L. Anchieri, F. Michaud, L. Winkelbach, J. Blöcher, Arizmendi Cárdenas, B. Sousa da Mota, E. Kalliga, A. Souleles, I. Kontopoulos, G. Karamitrou-Mentessidi, O. Philaniotou, A. Sampson, D. Theodorou, M. Tsipopoulou, I. Akamatis, P. Halstead, K. Kotsakis, D. Urem-Kotsou, D. Panagiotopoulos, C. Ziota, S. Triantaphyllou, O. Delaneau, J. D. Jensen, J. V. Moreno-Mayar, J. Burger, V. C. Sousa, O. Lao, A.-S. Malaspinas, and C. Papageorgopoulou. 2021. The genomic history of the Aegean palatial civilizations, Cell, 184, 1-22

[6] S. Daggumati and P. Z. Revesz. 2018. Data mining ancient script image data using convolutional neural networks. In Proceedings of the 22nd International Database Engineering and Applications Symposium, pages 267-272. ACM Press.

[7] S. Daggumati and P. Z. Revesz. 2021. A method of identifying allographs in undeciphered scripts and its application to the Indus Valley Script. Humanities and Social Sciences Communications, 8, 50.

[8] P. B. deMenocal. 2001. Cultural responses to climate change during the late Holocene. Science, 292, 5517, 667-673.

[9] E. Ehler, J. Novotný, A. Juras, M. Chyleński, O. Moravčík, and J. Pačes. 2019. A database of ancient human mitochondrial genomes, Nucleic Acids Research, 47, D1, p. D29-D32.

[10] A. Evans. 1935. The Palace of Minos at Knossos, vols. I-IV, MacMillan and Co, London, UK.

[11] M. Gimbutas. 1989. The Language of the Goddess, Thames \& Hudson Inc., New York, NY, USA.

[12] C. H. Gordon. 1966. Evidence for the Minoan Language, Ventnor Publ., Ventnor, NJ, USA.

[13] H. Haarmann. 2014.Roots of Ancient Greek Civilization: The Influence of Old Europe, McFarland \& Co. Publishing, Jefferson, NC, USA.

[14] J. R. Hughey, P. Paschou, P. Drineas, D. Mastropaolo, D. M. Lotakis, P. A. Navas, M. Michalodimitrakis, J. A. Stamatoyannopoulos, and G. Stamatoyannopoulos. 2013. A European population in Minoan Bronze Age Crete, Nature Communications, 4, p. 1861.

[15] J. Lazaridis, A. Mittnik, N. Patterson, S. Mallick, N. Rohland, S. Pfrengle, A. Furtwängler, A. Peltzer, C. Posth, A. Vasilakis, P. J. P. McGeorge, E. KonsolakiYannopoulou, G. Korres, H. Martlew, M. Michalodimitrakis, M. Ózsait, N. Özsait, A. Papathanasiou, M. Richards, S. A. Roodenberg, Y. Tzedakis, R. Arnott, D. M. Fernandes, J. R. Hughey, D. M. Lotakis, P. A. Navas, Y. Maniatis, J. A. Stamatoyannopoulos, K. Stewardson, P. Stockhammer, R. Pinhasi, D. Reich, J. Krause, and G. Stamatoyannopoulos. 2017. Genetic origins of the Minoans and Mycenaeans, Nature, 548, 214-218.

[16] N. Marinatos. 2010. Minoan Kingship and the Solar Goddess: A Near Eastern Koine, University of Illinois Press, Champaign, IL USA.

[17] P. Z. Revesz. 2016. A computer-aided translation of the Cretan Hieroglyph script. International fournal of Signal Processing, 1, 127-133.

[18] P. Z. Revesz. 2016. A computer-aided translation of the Phaistos Disk. International Journal of Computers, 10, 94-100.

[19] P. Z. Revesz. 2016. Bioinformatics evolutionary tree algorithms reveal the history of the Cretan Script Family. International fournal of Applied Mathematics and Informatics, 10, 67-76.

[20] P. Z. Revesz. 2017. Establishing the West-Ugric language family with Minoan, Hattic and Hungarian by a decipherment of Linear A, WSEAS Transactions on Information Science and Applications, 14, 1, 306-335.

[21] P. Z. Revesz. 2018. Spatio-temporal data mining of major European river and mountain names reveals their Near Eastern and African origins, 22nd European Conference on Advances in Databases and Information Systems, Springer LNCS 11019 , p. 20-32

[22] P. Z. Revesz. 2019. Art motif similarity measure analysis: Fertile Crescent, Old European, Scythian and Hungarian elements in Minoan culture, WSEAS Transactions on Mathematics, 18, 264-287.

[23] P. Z. Revesz. 2019. Minoan archaeogenetic data mining reveals Danube Basin and western Black Sea littoral origin, International fournal of Biology and Biomedical Engineering, 13, 108-120.

[24] P. Z. Revesz, M. P. Rashid, Y. Tuyishime. 2019. The design and implementation of AIDA: Ancient Inscription Database and Analytics system, Proc. 23rd Int. Database Engineering and Applications Symposium, ACM Press, pp. 292-297.

[25] Vahaduo tools for G25 admixture analysis, available at: http://g25vahaduo.genetics.ovh. 